\title{
Prognosis of Surgical Treatment for Degenerative Lumbar Spinal Stenosis: A Prospective Cohort Study of Clinical Outcomes and Health- Related Quality of Life Across Gender and Age Groups
}

\author{
Elisabeth Thornes ${ }^{*}, 1$, Nikolaos Ikonomou ${ }^{1}$ and Margreth Grotle ${ }^{2,3}$ \\ ${ }^{1}$ Martina Hansens Hospital, Oslo, Norway \\ ${ }^{2}$ FORMI (Communication Unit for Musculoskeletal Disorders), Oslo University Hospital, Norway \\ ${ }^{3}$ National Resource Centre for Rehabilitation in Rheumatology, Diakonhjemmet Hospital, Norway
}

\begin{abstract}
Degenerative lumbar spinal stenosis is a common condition and the most usual indication for spinal surgery in adult patients. The main objective of this study was to investigate clinical outcomes, health-related quality of life (HRQoL) and satisfaction among patients with a diagnosed lumbar spinal stenosis who were surgically treated, and whether these outcomes differed according to gender and age. Surgery was performed on 100 patients with clinical and radiological defined lumbar spinal stenosis. All patients completed questionnaires twice before surgery and at 6 weeks, 12 weeks, and 1 year postoperatively. Main outcomes were symptoms, physical function and patient satisfaction assessed by the Swiss Spinal Stenosis Questionnaire and HRQoL by the Short Form 36 health survey (SF36). There were large improvements in all clinical outcomes and in the physical subscales of the SF36. A marked reduction of average $32.3 \%$ was seen in symptoms already at 6 weeks follow-up. Physical function had improved with an average of $29.8 \%$ at 1 -year follow-up. There was no statistical significant effect of age and gender on symptoms and physical function. Patients more than 65 years were significantly less satisfied at the 1 -year follow-up as compared to the younger patients $(\mathrm{p}=0.012)$. This study showed that the majority of patients improved significantly in symptoms, physical function and physical HRQoL after surgery for degenerative lumbar spinal stenosis, regardless of age and gender. Age showed to be closely connected to satisfaction.
\end{abstract}

Keywords: Degenerative lumbar spinal stenosis, surgery, clinical course, symptoms, physical function, satisfaction, healthrelated quality-of-life.

\section{INTRODUCTION}

Degenerative lumbar spinal stenosis is the most frequent indication for spinal surgery in patients past 65 years $[1,2]$. Although numerous studies have been published, controversy still exists regarding the recommending of surgical treatment $[3,4]$. However, due to the severe torments these patients suffer, surgery is often offered [5]. Since H. Verbiest described the lumbar spinal stenosis with its pathogenesis and symptoms [6] and introduced the decompression surgery to reduce the constriction of the nerve tissue, surgery has been the most acknowledged treatment. During the last years, studies with high evidence have been published and report that the majority of the patients benefit from surgery both in diminished pain and gained function, faster and in larger extend than the conservative treatment approach [7-9].

It has been estimated that $80 \%$ of persons passed 70 years have a stenotic lumbar spine verified by $x$-ray [2]. With an increase of the elderly population, it is expected an increased incidence of patients with degenerative low back

*Address correspondence to this author at the Department of Orthopedics, Martina Hansens Hospital, Postbox 23, 1306 Bærum Postterminal, Norway; Tel: +47 675218 04; Fax: +47 675217 00;

E-mail: elisabeth.thornes@mhh.no problems [10]. According to estimations $1 / 18$ of persons past 65 years in western countries will be suffering from degenerative lumbar diseases and would accordingly need recommended treatment $[11,12]$. Hence, it is particularly important to explore whether surgical treatment is as useful for elderly people as for younger. Previous findings regarding the influence of age upon the effect of surgical treatment are controversial. Some studies have found that increasing age is associated with less favourable outcomes $[1,13]$, whereas others have found the opposite result [14]. Female gender has also shown to be connected with less satisfaction in several studies $[15,16]$. Whether or not the clinical outcomes after spinal surgery for lumbar spinal stenosis differ according to age and gender requires further research, as current knowledge is still insufficient.

The aim of this study was to investigate clinical outcomes, HRQoL and satisfaction among patients who were referred to and underwent surgical treatment for degenerative lumbar spinal stenosis, and whether these results differed according to gender and age.

\section{MATERIALS AND METHODS}

\section{Design and Setting}

We conducted a prospective cohort study of patients referred to surgical assessment and treatment due to lumbar spinal stenosis at Martina Hansens Hospital, a hospital close 
to Oslo in Norway. The hospital is specialized in elective surgery and treatment in orthopaedics and rheumatism. The study was approved by the Norwegian Committee of Ethics and followed the Helsinki convention. All included patients gave written informed consent for the study.

After the surgery the patients were followed at 6 weeks, 12 weeks, and 1 year. The 6 weeks follow-up contained a mailed questionnaire that was returned in an enclosed envelope, whereas for the 12 weeks and 1 year follow-up the questionnaire were administered during an appointment at the hospital.

\section{Patients and Recruitment}

All consecutive patients referred to the hospital due to degenerative lumbar spinal stenosis in the period between February 2004 and June 2007, were eligible. The patients were informed and asked to participate in the study when they were enlisted to surgery. One of the hospitals physical therapists administrated the information and questionnaires to the patients (ET). The majority of the patients that enrolled in the study, came from areas around Oslo, Akershus Country, in Norway.

Inclusion/exclution criterias: Patients who had clinically and radiologically (MRI) confirmed lumbar spinal stenosis, aged between 40 and 85 years, and who committed to participate in the study were included. Patients with malignancy, infection, an active, progressive arthritis in knee or hip joint, peripheral circular disease or a known polynevropathy were excluded from the study, as were patients who did not speak or read/write sufficient Norwegian. Two experienced surgeons were responsible to enrol the patients to surgery and choose the optimal surgical strategy for each patient.

\section{Baseline Assessment}

All patients filled in a comprehensive questionnaire consisting of sociodemographic, back pain-related variables and psychological variables. The outcome measures are accounted for in the next section. The comprehensive questionnaire was filled in twice before the surgery; first at the time the patients were enrolled to surgery (the questionnaire was returned in an enclosed envelope together with the signed consent) and second, on the day they were hospitalized. A mean score of the two assessments is referred to as the baseline values.

Sociodemographic characteristics included sex, age, total years of education, work status, living status and smokinghabits. Back pain variables included medical and surgical history data (duration of low back pain, previous back surgery, waiting time for surgery, co-morbidity), use of medication (analgesics, sleeping/relaxation), and pain intensity in back, leg(s), and other body area (on a $100-\mathrm{mm}$ visual analogue scale (VAS)).

The Oswestry Disability Index (ODI) [17] was added to supply information about physical functioning, in addition to a short-distance walk test (20. meters, assessed by seconds) [18]. The ODI is well known and appraised low back questionnaire with an end score between " 0 " and " 100 ", where " 0 " represent no problem and " 100 " total disabled.

\section{Outcome Measures}

Primary clinical outcome measure was the Swiss Spinal Stenosis Questionnaire (SSS). This is a disease specific instrument with three subscales [19-22] and is accounted as unweighted mean scores. The SSS symptom severity subscale has 7 questions with response categories from "1" to " 5 " where " 1 " represents no symptom and " 5 " represents severe symptoms, respectively. The SSS physical function subscale has 5 questions and SSS satisfaction subscale has 6 questions, both with response categories from "1" to " 4 ", where "1" represents best score (no physical function problem and very satisfied with treatment) and "4" represents lowest score (severe physical function problems and very dissatisfied by surgery).

The SSS satisfaction subscale was administrated only at 3- and 12-months follow-ups. According to Stucki et al, a mean score of 2.5 or lower can be used to define a successful outcome [21]. Furthermore, a change score of 0.5 or more at the SSS Symptom Severity and SSS Physical Function has been regarded as the minimal clinically important change [21].

The Short Form 36 health survey (SF36) was used to assess health-related quality-of-life (HRQoL) [23] more specifically by the Norwegian validated version [24]. The SF36 is a widely used generic instrument that measures 8 health constructs with reference to the past 4 weeks: physical functioning (10 items), role limitation due to physical problems (4 items), pain (2 items), general health (5 items), vitality (4 items), social functioning ( 2 items), role limitation due to emotional problems ( 3 items), and mental health (5 items). Scores range from 0 to 100 , with a higher score indicating better HRQoL. SF36 is regarded as a valuable tool for assessing the prognosis after surgical treatment for degenerative spinal stenosis [25]. Secondary outcome measures were the pain intensity scales and the ODI, which were administrated at all the follow-ups. After surgery, the patients also answered questions about attending in- or outpatient rehabilitation and of self managed training.

\section{Surgery and Postoperative Management}

All patients had their surgery done by the hospitals two senior surgeons. The patients were all individually assessed and the chosen surgery was regarded as optimal for each patient $[25,26]$. The intention was to release the pressure on nerve tissue by removing enough of the bone, facet joints and ligaments due to the compression. The procedure included a laminectomy with partial removal of bone from inferior aspect of one lamina and superior aspect of the subjacent lamina, excision of the flavum ligaments, and partial medial facetectomy. If there were calculated risk of lumbar instability, it was applied a segmental fusion. Instability was defined as degenerative spondylolisthesis of the spine warranting a stabilizing surgical procedure. The patients that underwent fusion were to use an orthosis for four months.

After the surgery the patients were told by trained physical therapists how to attend the first postoperative period regarding activity and rest. The patients were also given a simple home exercise program. After six weeks they 
were told to gradually return to or start organized training and normal daily living without anxiously considering their lumbar column.

\section{Statistical Analysis}

The Statistical Package of Social Science (SPSS), version 14.0 and 15.0, was used to analyse the data. Categorical data is presented by frequencies and percentage and numerical data by mean and standard deviation (SD). The baseline data were analysed according to gender with Chi-square test for categorical data and independent samples t-test for continuous data, respectively. Clinical course of symptoms, physical function and health-related quality of life (HRQoL) were analysed by repeated measures ANOVA (GLM univariate procedure/Mixed Models). The impact of gender and age on the outcome measures was analysed by including these factors as covariates in the repeated measures ANOVA.

Cross-tables and multivariate logistic regression analysis were used to analyse the results for the SSS Satisfaction subscale according to age and gender at the follow-ups. A dichotomised SSS Satisfaction was used as outcome with the recommended cut-off of 2.5 (2.5 or less=satisfied with surgical outcome, see above). Differences across gender and age groups in patient satisfaction at 12-months were analysed both in crude and adjusted analyses (adjusted for age, gender and SSS Physical function at baseline).

\section{RESULTS}

\section{Patient Characteristics}

Baseline characteristics of the 100 included patients, 55 women and 45 men, are presented in Table 1 . The mean age at the time of surgery was 68.1 years and the mean duration of low back pain was 15.1 years. Women had lower level of education, were more likely to live alone, had higher pain intensity in lower back and in other body areas, and were more functional disabled as compared to men before surgery. There was no significant difference in age, smoking, work status, and most of the back pain variables such as duration of low back pain, use of medication or pain intensity in legs.

Table 1. Baseline Characteristics of Patients with Degenerative Lumbar Spinal Stenosis at Entry into the Study (n=100)

\begin{tabular}{|c|c|c|c|c|}
\hline Variable & No $(\%)$ or Mean (sd) ${ }^{1}$ & Female $(n=55)$ & Male (n=45) & p-Value for Difference Between Gender \\
\hline \multicolumn{5}{|l|}{ Sociodemographic Variables } \\
\hline Age (years) & $68,1(10.3)$ & $68(11.1)$ & $68.3(9.2)$ & .85 \\
\hline Age 65 years or more & $62(62)$ & $33(60)$ & $29(64.4)$ & .40 \\
\hline Education $(<12$ years $)$ & $65(65.7)$ & $43(78.2)$ & $22(48.9)$ & .002 \\
\hline Smoking (yes) & $21(23.9)$ & $12(25.5)$ & $9(22)$ & .8 \\
\hline Work status (\% not employed) & $68(68.7)$ & $38(69.1)$ & $30(68.2)$ & .6 \\
\hline Living status (alone) & $24(25.3)$ & $19(36.5)$ & $5(11.6)$ & .008 \\
\hline \multicolumn{5}{|l|}{ Back Pain Variables } \\
\hline History of low back pain (years) & $13.9(14.7)$ & $12.8(14.3)$ & $15.2(15.2)$ & .43 \\
\hline Waiting list for surgery (weeks) & $8.3(5.5)$ & $8(5.7)$ & $8.7(5.2)$ & .55 \\
\hline Co-morbidity (yes) & $65(65)$ & $36(34.5)$ & $29(64.4)$ & .54 \\
\hline Earlier LB surgery (yes) & $13(13)$ & $5(9.1)$ & $8(17.8)$ & .2 \\
\hline Pain medication daily (yes) & $47(47.5)$ & $29(52,7)$ & $18(40.9)$ & .3 \\
\hline Sleeping/relaxation (yes) & $34(37.8)$ & $20(40.8)$ & $14(34.1)$ & .66 \\
\hline Pain intensity, back (0-100) & $72.2(21.3)$ & $75.9(19.8)$ & $66.4(24.3)$ & .05 \\
\hline Pain intensity; legs ( $0-100)$ & $76.1(19.0)$ & $76.9(18.8)$ & $75.6(19.1)$ & .9 \\
\hline Pain intensity, other area $(0-100)$ & $46.8(30.3)$ & $53.4(30.4)$ & $19.2(28.7)$ & .03 \\
\hline Oswestry DisabilityIndex $(0-100)$ & $37.8(12.2)$ & $41.3(10.6)$ & $33.6(12.7)$ & .001 \\
\hline Walking ability (20m in sec.) & $18.1(6.4)$ & $19.9(6.6)$ & $16.0(5.4)$ & .01 \\
\hline $\mathrm{SSS}^{2}$ symptom severity $(1-5)$ & $3.33(.46)$ & $3.37(.46)$ & $3.28(.46)$ & .35 \\
\hline $\mathrm{SSS}^{2}$ physical function (1-4) & $2.54(.58)$ & $2.67(.54)$ & $2.39(.60)$ & .02 \\
\hline \multicolumn{5}{|l|}{ Health-Related QoLife (SF36) $\left(0-100^{3}\right)$} \\
\hline Physical functioning & $37.5(20.3)$ & $31.4(16.9)$ & $43.8(22.4)$ & .003 \\
\hline Role limitations-physical & $13.8(25.7)$ & $10.6(23.9)$ & $17.1(27.2)$ & .22 \\
\hline Bodily pain & $30.4(18.0)$ & $27.7(16.7)$ & $33.1(19.3)$ & .14 \\
\hline General health & $63.0(20.1)$ & $59.0(22.2)$ & $66.1(18.9)$ & .10 \\
\hline Vitality & $41.3(17.4)$ & $35.8(15.5)$ & $47.6(17.5)$ & .001 \\
\hline Social functioning & $54.6(25.4)$ & $49.0(24.7)$ & $60.2(25.8)$ & .03 \\
\hline Role limitations-emotional & $49.8(44.1)$ & $44.7(46.0)$ & $55.8(41.6)$ & .23 \\
\hline Mental health & $74.0(17.5)$ & $70.2(16.1)$ & $78.3(18.3)$ & .02 \\
\hline SF36Phys. function sum score & $21.0(20.6)$ & $18.0(19.1)$ & $24.5(22.0)$ & .13 \\
\hline SF36 Mental health sum score & $67.7(26.1)$ & $63.0(26.6)$ & $73.2(24.7)$ & .06 \\
\hline
\end{tabular}

${ }^{1}$ Continuous variables are presented by means with standard deviations in parentheses, and categorical variables by frequencies with percentages in parentheses. ${ }^{2} \mathrm{SSS}=$ Swiss Spinal Stenosis Questionnare. ${ }^{3}$ Higher scores indicate better health. 
At 6 weeks postal follow-up, a total of 32 patients did not return the questionnaire, and because of the limited time period ahead to the next follow up, these are missing values. However, none of these patients was dropouts. At 12 weeks and 1 year, 10 and 11 patients, respectively, were lost to follow up, due to different reasons. At earlier follow-ups 8 of these 11 non-repliers regarded themselves as satisfied.

At 1 year, two patients were still in rehabilitation after a total hip replacement, one patient suffered from dementia and did not remember the surgery; one patient was into a cancer treatment, one patient was deceased and six patients were out of reach for unknown reasons. The 1-year followup results are based on 89 patients $(89 \%)$.

Only 57 patients responded to the SF36, There was no difference in baseline characteristics between the responders and non-responders, neither at the 6 weeks nor at the 1 year follow-up ( $\mathrm{p}>0.1)$.

Furthermore, the two preoperative scorings on SSS and pain intensity variables showed that the torments connected to the lumbar spinal stenosis were stable during the time the patients were enlisted to surgery ( 8.3 weeks) $(\mathrm{p}>0.2)$.

\section{Surgical Treatment and Rehabilitation}

Most of the patients (80\%) underwent decompression of one or two spinal levels (Table 3). Eight patients, all female, had an additional fusion and used an orthosis during the first 4 months after surgery. Surgical complications occurred in 11 patients (11\%). 3 wound infections ( 1 deep and 2 superficial), 4 wound revisions, 3 dural tears and 1 myocardial infarction. None of these complications caused any residual problems. After surgery, 32 patients $(34.7 \%, \mathrm{n}=95)$ left hospital for a stay at a rehabilitation centre. The mean length of the stay was 2.5 weeks (SD 1.5, min $0.5-\max 8.0)$. At 1 year follow-up, $69.3 \%(n=61)$ of the patients reported they were doing more than one physical activity weekly to keep in shape.

\section{Clinical Course During the First Follow-Up Year}

There were large and statistically significant improvements in symptom severity and physical function during the first year of follow-up $(p<0.001)$. The most marked reduction was seen in SSS Symptom severity during the first 6 weeks after surgery with $32.3 \%$, whereas the SSS Physical function had largest improvement at 1-year followup with $29.8 \%$.

Through the whole follow-up period there was a tendency that women and persons of 65 years or more had more symptoms and poorer physical function as compared to men and persons less than 65 years (Fig. 1). However, according to analyses for interaction between age and time course, and gender and time course respectively, there were no statistical significant differences for SSS Symptom severity $(p=0.201$ and $p=0.605)$ and SSS Physical function $(\mathrm{p}=0.947$ and 0.552$)$. There was also a significant improvement during the year of follow-up in the VAS pain scales $(\mathrm{p}<0.001)$ and the Oswestry Disability Index $(\mathrm{p}<0.001)$.

\section{Clinical Course of Health-Related Quality-of-Life}

Before surgery the patients had poor scores in many of the SF36 subscales, in particular in physical function, role limitations-physical, bodily pain, and vitality (Table $\mathbf{1}$ ). Although there was a tendency that women and persons of 65 years or more had poorer scores in the SF36 Physical and Mental sum scores, there were no significant differences at baseline (Table 1). During the 1 year follow-up there were significant improvements in the SF36 Physical function sum score, whereas there were no statistical changes in SF36 Mental function sum score (Fig. 2). There were no statistically significant interaction effects of the SF36 sum scores and age and gender, respectively ( $p>0.124)$.

Table 2. Surgical Treatment According to Gender and Age

\begin{tabular}{|c|c|c|c|c|c|c|}
\hline \multirow[b]{2}{*}{$\begin{array}{c}\text { Age } \\
\text { Groups }\end{array}$} & \multicolumn{3}{|c|}{ Decompression } & \multirow{2}{*}{$\begin{array}{c}\text { Decompression and Fusion } \\
\text { Female/Male } \\
9 / 0\end{array}$} & \multirow{2}{*}{$\begin{array}{c}\text { X-Stop } \\
\text { Female/Male } \\
1 / 3\end{array}$} & \multirow{2}{*}{$\begin{array}{c}\text { Total Female/Male } \\
\text { Female } / \text { Male } \\
55 / 45\end{array}$} \\
\hline & $\begin{array}{c}1 \text { Level } \\
\text { Female/Male } \\
19 / 21\end{array}$ & $\begin{array}{c}2 \text { Levels } \\
\text { Female/Male } \\
20 / 19\end{array}$ & $\begin{array}{c}3 \text { Levels } \\
\text { Female/Male } \\
6 / 2\end{array}$ & & & \\
\hline 40-64 years & $8 / 8$ & $9 / 7$ & $1 / 1$ & $4 / 0$ & $0 / 0$ & $22 / 16$ \\
\hline $65-90$ years & $11 / 13$ & $11 / 12$ & $5 / 1$ & $5 / 0$ & $1 / 3$ & $33 / 29$ \\
\hline
\end{tabular}

Table 3. Surgical Treatment According to Age and ASA Classification

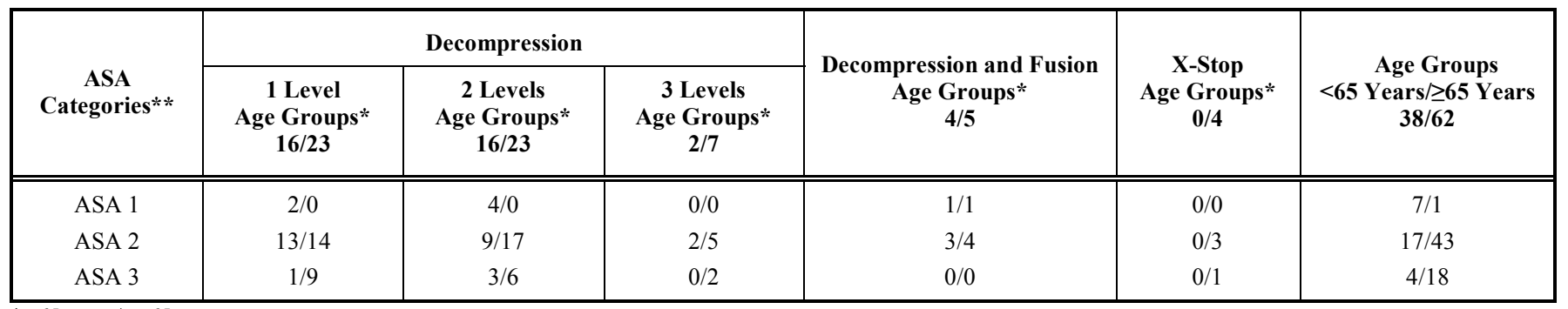

$*<65$ years $/=>65$ years.

** ASA The American Society of Anesthesiologists (ASA) Physical Status classification system was initially created in 1941 by the American Society of Anesthetists, an organization that later became the ASA. 

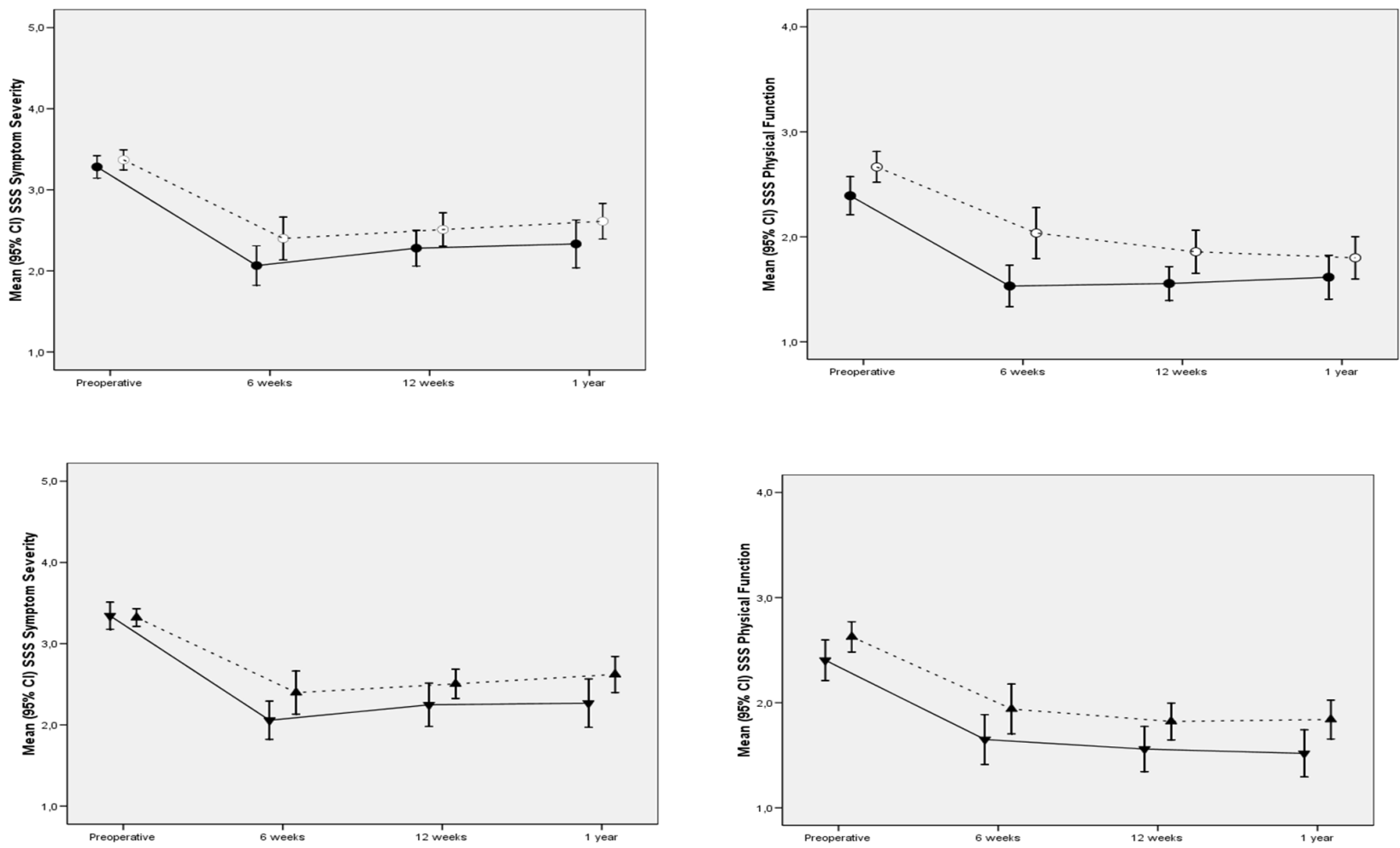

Fig. (1). SSS Symptom and Function scores (means with 95\% CI) in female (--0--), and male (-•-) patients with lumbar spinal stenosis before, 6 weeks, 12 weeks and 1 year after treated with surgery surgery. Under, the similar figures for patients $<65$ years $(-\nabla-)$ and 65 years or more (-- $\mathbf{\Delta}--)$ are presented.

\section{Patient Satisfaction}

Approximately $76 \%$ of the patients at 3 months and $70 \%$ of the patients at 12 months follow-up regarded themselves as satisfied with surgical outcome, according to a cut-off at " 2.5 " on the SSS Satisfaction scale. Patient satisfaction differed significantly across younger and older age groups; more people of 65 years or more $(81.5 \%)$ were not satisfied with surgery result at 12 -months as compared to people less than 65 years $(18.5 \%)($ Chi square $p=0.012)$. There was also a tendency that women $(70.4 \%)$ were less satisfied with surgery result at 12-months as compared to men (29.6\%), but this association was not statistically significant (Chi square $\mathrm{p}=0.055$ ). In a multivariate regression model, adjusting for SSS Physical Function at baseline, people of 65 years or more were four times more likely to be not satisfied with surgery result as compared to those less than 65 years (Odds Ratio 4.0, 95\% CI; 1.25 to $12.9, \mathrm{p}=0.02$ ). Female gender showed a strong tendency to be associated with less satisfaction at 1 year, but did not reach the level of significance in the adjusted analysis $(\mathrm{p}=0.08)$.

\section{DISCUSSION}

\section{Summary of Key Findings}

There were large improvements in symptoms, function, and several aspects of health-related quality-of-life among patients who received surgical treatment due to degenerative lumbar spinal stenosis. The majority of the patients were also highly satisfied with the treatment results. Although there was a trend that elderly patients ( $\geq 65$ years) and women scored higher on the primary SSS subscales (symptoms and function) and in the SF36 sum scores throughout the followup period, there was no statistical significant effect of age and gender in these analyses. The only exception was that elderly patients were significantly less satisfied at 1-year follow-up as compared to the younger patients.

\section{Study Population}

The patients in our study population had the same level of spinal stenosis symptoms and physical function measured by SSS questionnaire, as found in a recent Finnish study [14]. There were also large similarities, both in regard the patient's duration of low-back history - 15.8 years in the Finnish material vs 15.1 years in our material - and in the gender distribution - 58\% vs 55\% female, respectively. Mean age in our material was similar to the sample in the Maine study [7], but slightly older compared to the Finnish study [14] and the SPORT study [9]. Furthermore, the present study's baseline scores of the SF 36 was similar both to those reported in the SPORT study [9] and the reference values accounted by Zanoli et al., [25].

\section{Clinical Course After Surgery in Comparison with Other Studies}

The change in the SSS Symptom Severity subscale was largest at 6-weeks follow-up, which is similar to what Sinikallio et al., reported in 2007 [14]. Weinstein et al. 

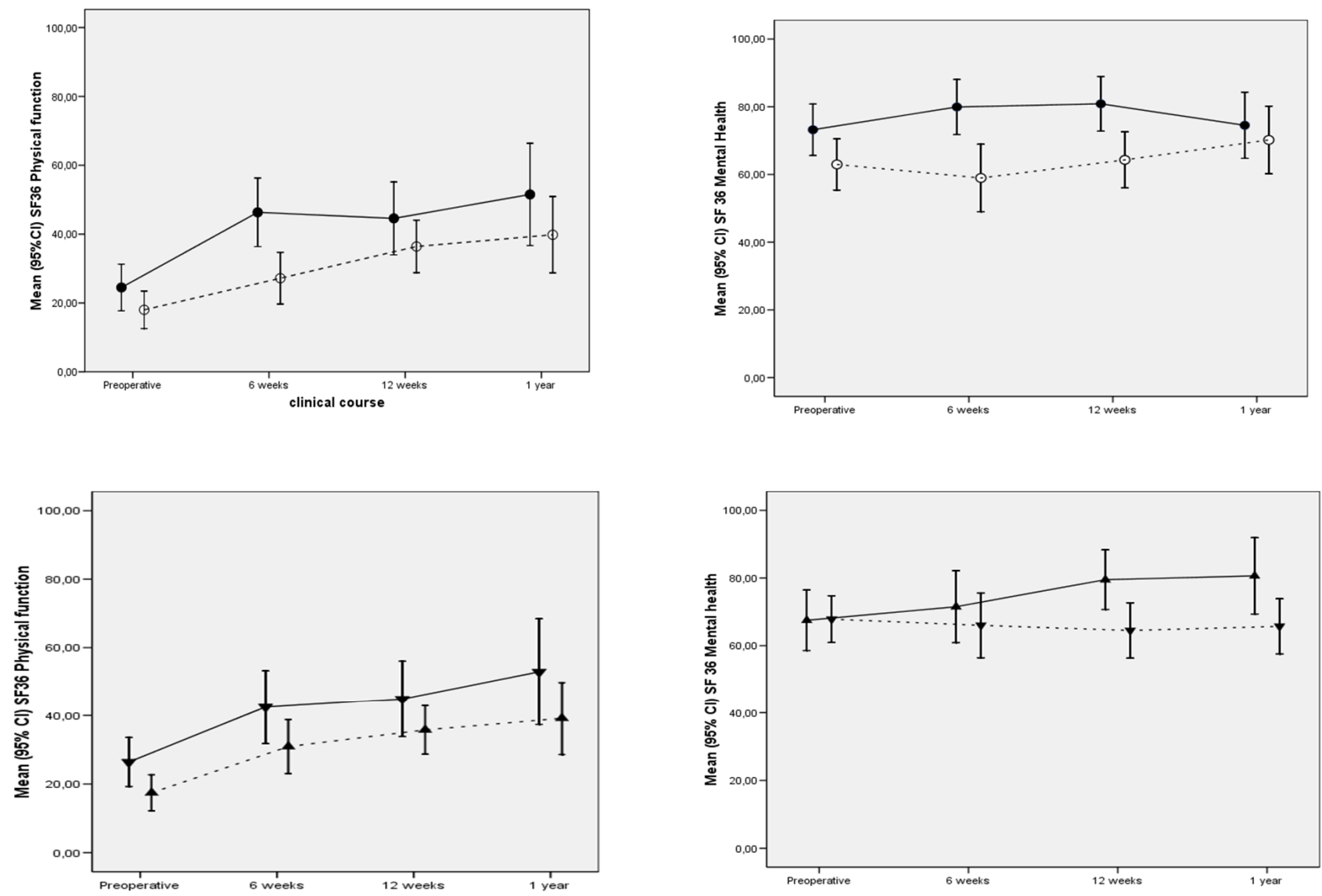

Fig. (2). SF36 Physical and Mental health scores (means with 95\% CI) in female (--०--) and male (-•-) patients with lumbar spinal stenosis, 6 weeks, 12 weeks and 1 year after treated with surgery surgery. Under, the similar figures for patients $<65$ years $(-\nabla-)$ and 65 years or more (-- $\boldsymbol{\Delta}$--) are presented.

reported the same early recovery using a different outcome measure (Stenosis Bothersomeness Index) [9].

The degree of functional improvement according to the ODI in our study is comparable to the findings of both Malmivaara el al [8] and Weinstein et al. [9]. Furthermore, the improvement in the physical subscales of the SF-36 in the present study can be compared to the findings in the SPORT study [9]. The reported improvements [9] occurred throughout the first year of followup.

\section{The Impact of Age and Gender}

Before surgery the women in this study population had significantly poorer scores in several of the clinical outcomes and the SF36 subscales, which could indicate that women seem to postpone surgery longer than men. This is also commented in the study by Katz et al., [27]. Despite this difference between the women and men at baseline, the change in the clinical outcomes and HRQoL were similar across the gender.

Similarly, there was a tendency that elderly patients of more than 65 years scored higher in the outcome measures at all time points than younger patients, but this difference was not statistical significant. Most previous studies report that increasing age is associated with less improvement after spinal stenosis surgery $[1,13]$.
These results show that it is important to consider the baseline level of the outcomes when interpreting the change scores at follow-ups; both younger and older patients as women and men seem to have similar improvement according to the clinical outcomes, but they tend to score at different levels throughout the whole follow-up period. We have not found any support elsewhere in the literature to these findings.

\section{Patient Satisfaction}

The proportion of patients who were satisfied by the surgery outcome in the present study is very similar to what other report $[9,14]$, approximately two third $(2 / 3)$ of the patients. In what extent the patients regards themselves as satisfied with the change due to surgery is probably connected to various factors as the actual level of symptoms, their physical and social ability. K. Yamashita et al., [13] underline that the patients' satisfaction level seem to be closer associated with the end results; the actual symptom level, than with the change in scores.

\section{Strengths and Weaknesses}

This study has some principal shortcomings. First, the sample size is relatively small, which provides less statistical power than what's optimal, in particular in the SF36, which had a lot of missing data. Second, we did not include physical fitness tests to evaluate the patients' general physical condition (heart/lung function). The patients' physical condition test might 
have helped us to guide the patients both pre-operatively and before post-surgical rehabilitation.

The strength of the study is the close follow up the first year, which has shown that the largest change symptom scores occurred between surgery and 6 weeks. Another positive factor is that our comprehensive questionnaire contained many acknowledged schemes, and our results could through them be compared with the results of others.

\section{Clinical Implications}

The results from this study can be useful for clinical treatment, both before and after surgery, as well as for further research on these patients. In example, the findings showing that the release of torments appeared during the first 6 weeks after surgery can be useful when identifying patients who need further post-operative management. The result can also be used for planning further research in this area. There is a need for further research on whether pre-operative training could improve the physical ability in the elderly and female patients.

\section{CONCLUSION}

This study has shown that patients who received surgical treatment due to lumbar spinal stenosis had large improvements in symptoms, function, and several aspects of health-related quality of life during the first year following surgery. There was no statistical significant impact of age and gender on symptoms, function and quality-of-life during follow-up.

\section{ACKNOWLEDGMENT}

The Norwegian Association for Physiotherapy has contributed with financial support for this study. Ethical approval was granted by the Norwegian Committee of Ethics.

\section{CONFLICT OF INTEREST}

None declared

\section{REFERENCES}

[1] Katz JN, Stucki G, Lipson SJ, Fossel AH, Grobler LJ, Weinstein JN. Predictors of surgical outcome in degenerative lumbar spinal stenosis. Spine 1999; 24: 2229-33.

[2] Szpalski M, Gunzburg R. Lumbar spinal stenosis in the elderly: an overview. Eur Spine J 2003; 12(Suppl 2): S170-S75.

[3] Athiviraham A, Yen D. Is spinal stenosis better treated surgically or nonsurgically? Clin Orthop Relat Res 2007; 458: 90-3.

[4] Gibson JN, Waddell G. Surgery for degenerative lumbar spondylosis. Cochrane Database Syst Rev 2005; CD001352.

[5] Jonsson B, Stromqvist B. Symptoms and signs in degeneration of the lumbar spine. A prospective, consecutive study of 300 operated patients. J Bone Joint Surg Br 1993; 75: 381-5.

[6] Verbiest H. A radicular syndrome from developmental narrowing of the lumbar vertebral canal. J Bone Joint Surg Br 1954; 36-B: 230-37.

[7] Atlas SJ, Keller RB, Robson D, Deyo RA, Singer DE. Surgical and nonsurgical management of lumbar spinal stenosis: four-year outcomes from the maine lumbar spine study. Spine 2000; 25: 556-62.
[8] Malmivaara A, Slatis P, Heliovaara M, et al. Surgical or nonoperative treatment for lumbar spinal stenosis? A randomized controlled trial. Spine 2007; 32: 1-8.

[9] Weinstein JN, Tosteson TD, Lurie JD, et al. Surgical vs nonsurgical therapy for lumbar spinal stenosis. N Engl J Med 2008; 358: 794-810.

[10] Miyamoto H, Sumi M, Uno K, Tadokoro K, Mizuno K. Clinical outcome of nonoperative treatment for lumbar spinal stenosis, and predictive factors relating to prognosis, in a 5-year minimum follow-up. J Spinal Disord Tech 2008; 21: 563-8.

[11] Ciol MA, Deyo RA, Howell E, Kreif S. An assessment of surgery for spinal stenosis: time trends, geographic variations, complications, and reoperations. J Am Geriatr Soc 1996; 44: 285-90.

[12] Sengupta DK, Herkowitz HN. Lumbar spinal stenosis. Treatment strategies and indications for surgery. Orthop Clin North Am 2003; 34: 281-95.

[13] Yamashita K, Ohzono K, Hiroshima K. Five-year outcomes of surgical treatment for degenerative lumbar spinal stenosis: a prospective observational study of symptom severity at standard intervals after surgery. Spine 2006; 31: 1484-90.

[14] Sinikallio S, Aalto T, Airaksinen O, et al. Lumbar spinal stenosis patients are satisfied with short-term results of surgery - younger age, symptom severity, disability and depression decrease satisfaction. Disabil Rehabil 2007; 29: 537-44.

[15] Mariconda M, Zanforlino G, Celestino GA, Brancaleone S, Fava R, Milano C. Factors influencing the outcome of degenerative lumbar spinal stenosis. J Spinal Disord 2000; 13: 131-7.

[16] Shabat S, Folman Y, Arinzon Z, Adunsky A, Catz A, Gepstein R. Gender differences as an influence on patients' satisfaction rates in spinal surgery of elderly patients. Eur Spine J 2005; 14: 1027-32.

[17] Fairbank JC, Pynsent PB. The Oswestry Disability Index. Spine 2000; 25: 2940-52.

[18] Bassey EJ, Fentem PH, MacDonald IC, Scriven PM. Self-paced walking as a method for exercise testing in elderly and young men. Clin Sci Mol Med Suppl 1976; 51: 609-12.

[19] Pratt RK, Fairbank JC, Virr A. The reliability of the Shuttle Walking Test, the Swiss Spinal Stenosis Questionnaire, the Oxford Spinal Stenosis Score, and the Oswestry Disability Index in the assessment of patients with lumbar spinal stenosis. Spine 2002; 27: 84-91.

[20] Stucki G, Liang MH, Fossel AH, Katz JN. Relative responsiveness of condition-specific and generic health status measures in degenerative lumbar spinal stenosis. J Clin Epidemiol 1995; 48: 1369-78.

[21] Stucki G, Daltroy L, Liang MH, Lipson SJ, Fossel AH, Katz JN. Measurement properties of a self-administered outcome measure in lumbar spinal stenosis. Spine 1996; 21: 796-803.

[22] Thornes E, Grotle M. Cross-cultural adaptation of the Norwegian version of the spinal stenosis measure. Eur Spine J 2008; 17: 456-62.

[23] Ware JE Jr, Sherbourne CD. The MOS 36-item short-form health survey (SF-36). I. Conceptual framework and item selection. Med Care 1992; 30: 473-83.

[24] Loge JH, Kaasa S. Short form 36 (SF-36) health survey: normative data from the general Norwegian population. Scand J Soc Med 1998; 26: 250-8.

[25] Zanoli G, Jonsson B, Stromqvist B. SF-36 scores in degenerative lumbar spine disorders: analysis of prospective data from 451 patients. Acta Orthop 2006; 77: 298-306.

[26] de G, I, Prak A, Bierma-Zeinstra S, Thomas S, Peul W, Koes B. Diagnosis of lumbar spinal stenosis: a systematic review of the accuracy of diagnostic tests. Spine 2006; 31: 1168-76.

[27] Katz JN, Wright EA, Guadagnoli E, Liang MH, Karlson EW, Cleary PD. Differences between men and women undergoing major orthopedic surgery for degenerative arthritis. Arthritis Rheum 1994; 37: 687-94. 